\title{
The IUCr crystal growing competition for schoolchildren
}

\author{
Luc Van Meervelt $^{1}$ \\ ${ }^{1}$ Chemistry Department KU Leuven, Leuven, Belgium \\ E-mail: luc.vanmeervelt@kuleuven.be
}

As part of the celebrations for the International Year of Crystallography in 2014 the IUCr has started to organize a worldwide crystal growing competition which now has reached its fourth edition. The competition is open to schoolchildren of primary or secondary schools (maximum age is 18) and invites them to explore the exciting, but sometimes frustrating world of growing crystals. Students should convey their experience of growing crystals through a video no longer than four minutes. Use of the mother language of the participants is recommended together with the use of English subtitles when applicable. The video should show in a creative way the experimental work carried out and illustrate its theoretical background. A judging panel nominated by the IUCr evaluates the entries according to six criteria: creativity, aesthetic value, description of working plan and experimental work, clarity of explanations, scientific background and safety. Currently a gold, silver and bronze medal is awarded to the winning contributions in three age categories (under 11, 11-15 and 15-18) together with a 'Young crystal growers' certificate.

For its first edition in 2014 IUCr was happy to receive 87 videos from 19 different countries (together with 53 essays from 11 countries). A total of 85 entries was submitted in 2015 (from 12 countries), while in 2016 the judging panel had to evaluate 72 videos (from 12 countries). The top three countries for submissions over the three editions is: Argentina (84 videos), Singapore (28 videos) and Vietnam (25 videos).

Winning videos are freely available from the IUCr website and can be further used for teaching purposes and motivating other young pupils to learn more about crystals! This collection of laureates contains videos showing in great detail all steps of growing single crystals, including the theoretical background, as well as how to grow nice geodes or even Cinderella's missing shoe. A group of very talented pupils even shows how to use the harvested single crystals to determine the index of refraction of the material.

National and regional crystal growing competitions are invited further to stimulate their participants to submit also videos to this worldwide competition. The closing date of the 2017 edition is 19 November 2017. Countries interested to start a new regional or national competition can find additional information to start up a new competition on the website of our international competition.

[1] iycr2014.org/participate/crystal-growing-competition-2017

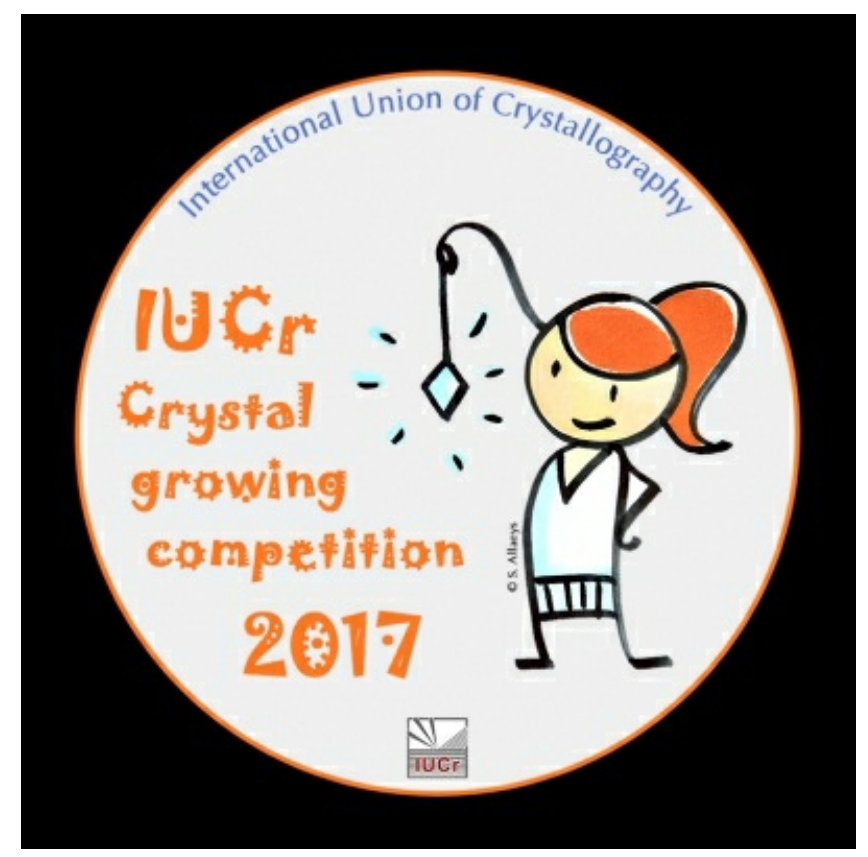

Keywords: crystal growing, competition, $\mathrm{IYCr}$ 